\title{
POTÁSSIO, SÓDIO E CRESCIMENTO INICIAL DE ESPÉCIES FLORESTAIS SOB SUBSTITUIÇÃO DE POTÁSSIO POR SÓDIO ${ }^{1}$
}

\begin{abstract}
Maykom Ferreira Inocencio ${ }^{2}$, Janice Guedes de Carvalho ${ }^{3}$ e Antonio Eduardo Furtini Neto ${ }^{3}$
RESUMO - A substituição de potássio (K) por sódio (Na) é reconhecida na literatura por aumentar a produtividade de algumas plantas, porém se conhece pouco sobre o comportamento em espécies florestais. Por isso, o objetivo deste estudo foi avaliar o crescimento inicial de Enterolobium contortisiliquum e Sesbania virgata na substituição de K por Na em solução nutritiva de Hoagland e Arnon. O esquema fatorial foi 2 x 5, sendo duas espécies florestais e cinco níveis de substituição $(0 ; 33,3 ; 50 ; 66,6$; e 100\%), com quatro repetições. O experimento foi instalado em vasos Leonard com capacidade para $1 \mathrm{~L}$, com a troca periódica da solução nutritiva. A colheita foi realizada aos 50 dias após o início do estudo, quando se avaliaram as características morfométricas das mudas. O material foi lavado e seco, e determinou-se a matéria seca das raízes, das folhas e do caule. O material radicular e o da parte aérea foram triturados e submetidos às análises de $\mathrm{K}$ e Na. Por cálculo, obtiveram-se a matéria seca da parte aérea (caule + folhas), a razão de raízes/parte aérea e o acúmulo de K e Na nas raízes e na parte aérea. A substituição de K por Na promoveu diferenças significativas no desenvolvimento das mudas, nos teores e acúmulos de K e Na. A espécie Sesbania virgata apresentou o melhor desenvolvimento inicial e acumulou maior quantidade de $\mathrm{K}$ e Na na parte aérea.
\end{abstract}

Palavras-chave: Crescimento inicial; Leguminosa florestal; Estresse salino.

\section{INITIAL GROWTH, UPTAKE AND BUILD UP OF K AND NA IN TWO LEGUMES FOREST TREE SPECIES UNDER REPLACEMENT OF K BY Na}

\begin{abstract}
The replacement of potassium ( $\mathrm{K}$ ) for sodium ( $\mathrm{Na}$ ) is recognized in the literature to increase some plants productivity, but little is known about the behavior in forest tree species. Therefore, the objective of this study was to evaluate the initial growth of Enterolobium contortisiliquum and Sesbania virgata in replacement of $\mathrm{K}$ by $\mathrm{Na}$ in Hoagland and Arnon nutrient solution. The factorial design was $2 \times 5$, consisting of two species and five substitution levels of $\mathrm{K}$ for $\mathrm{Na}(0 ; 33.3 ; 50,66.6$ and 100\%), with four replications. The experiment was conducted in Leonard pots with $1 \mathrm{~L}$ capacity, with periodic exchange of nutrient solution. The plants were harvested 50 days after the start of the study, when we evaluated the morphometric characteristics. The material was washed, dried and determined dry matter of roots, leaves and stem. Root and shoot materials were ground and analyzed for K and Na content. The shoot dry matter (stem + leaves), the ratio of root $/$ shoot and build up of $K$ and Na in roots and shoot were obtained by calculating. The replacement of K by Na promoted significant differences in plant development, content and build up of K and Na. The species Sesbania virgata showed the best initial growth and accumulated higher amount of K and Na in the shoots.
\end{abstract}

Keywords: Initial growth; Legumes forest tree species; Salt stress.

\footnotetext{
${ }^{1}$ Recebido em 25.01.2011 aceito para publicação em 07.11.2013.

2 Programa de Pós-Graduação em Ciência do Solo, Universidade Federal de Lavras, Lavras, Brasil. E-mail: <maykomagronomia@yahoo.com.br>

${ }^{3}$ Departamento de Ciência de Solo da Universidade Federal de Lavras, Lavras, Brasil. E-mail: $<$ janicegc@des.ufla.br $>$ e $<$ afurtini@dcs.ufla.br>.
} 


\section{INTRODUÇÃO}

O sódio $(\mathrm{Na})$ é um elemento químico presente em altos teores em solos pouco intemperizados (KORNDORFER, 2007), no entanto não é classificado como nutriente, pois não atende, aos critérios de essencialidade das plantas, exceto em uma única espécie, a Atriplex versicaria (MARSCHNER, 1995; FAQUIN, 2005). Na nutrição mineral de plantas, o Na é classificado como elemento benéfico, pois, quando presente no solo ou na solução nutritiva, promove o aumento da produtividade de algumas plantas. $\mathrm{O} \mathrm{Na}$ é absorvido na forma iônica $\mathrm{Na}^{+}$e possui alta mobilidade nos tecidos vegetais, com uma concentração variando entre 0,013 e $35,1 \mathrm{~g} \mathrm{~kg}^{-1}$ na matéria seca da parte aérea. Os sintomas da toxidez de $\mathrm{Na}$ são o murchamento, o amarelecimento, a redução do crescimento e da produtividade. $\mathrm{O} \mathrm{Na}$ pode substituir parcialmente o K atuando na ativação enzimática da ATPase, na osmorregulação, na absorção de macronutrientes, na permeabilidade das células, na síntese de carboidratos, na conversão da frutose em glicose, na abertura e fechamento estomático, no vigor de plantas e no transporte de gás carbônico $\left(\mathrm{CO}_{2}\right)$ para as células das plantas C4 (KORNDORFER, 2007).

O processo de sodificação dos solos ocorre pelo acúmulo de Na devido à menor precipitação pluviométrica em relação à taxa de intemperismo dos minerais primários do solo (FAQUIN, 2005; KORNDORFER, 2007). Mesmo os solos com predomínio de óxidos (de ferro e de alumínio) na fração argila podem apresentar altos teores de $\mathrm{Na}$, por causa do uso inadequado de água de irrigação rica em sais (SOUZA, 1995; BLANCO et al., 2002). No Brasil, o excesso de sais no solo ocorre naturalmente no semiárido nordestino, onde se estima que nove milhões de hectares, sendo $69 \%$ desses encontrados nos Estados da Bahia e do Ceará (GHEYI; FAGERIA, 1997). Devido ao alto teor salino nessas áreas e ao baixo potencial agrícola, esses locais podem ser destinados à preservação ambiental ou reflorestamento com plantas adaptadas ao excesso de $\mathrm{Na}$.

As plantas são classificadas em quatro grupos, de acordo com a tolerância ao $\mathrm{Na}$ : I: compreende aquelas que elevam a produtividade com a substituição parcial de K por Na; II: que respondem à substituição, porém possuem ligeira queda na produtividade em relação ao primeiro grupo; III: que são indiferentes à substituição; e IV: que na substituição de qualquer proporção de
$\mathrm{K}$ por Na reduz a produtividade (FAQUIN, 2005; KORNDORFER, 2007). Os principais representantes do grupo I são a beterraba, a beterraba-forrageira, o nabo, a acelga, o repolho, o rabanete, o algodoeiro, a ervilha, o coqueiro, o linho, o trigo e o espinafre. Porém, o efeito significativo do Na só ocorre desde que se tenha um mínimo necessário de K pela planta (MARSCHNER, 1995).

Para a revegetação de áreas degradadas por sais, são necessárias espécies pioneiras e tolerantes ao excesso de Na no solo. Na literatura, algumas espécies como o Enterolobium contortisiliquum e a Sesbania virgata se apresentam com tais características, porém não há registro do seu desenvolvimento em áreas sodificadas. O E. contortisiliquum, também conhecido como tamboril e orelha-de-macaco, é uma espécie da família Leguminosae, higrófita e se desenvolve rapidamente em solos degradados (LORENZI, 1998). A S. virgata é uma espécie da família Leguminosae, arbórea, pioneira e eficiente na fixação biológica de nitrogênio (CHAVES et al., 2003), com protófilos compostos com quatro a nove pares de folíolos pequenos e opostos (ARAÚJO et al., 2004).

Nesse sentido, o objetivo deste estudo foi avaliar o crescimento inicial, teores e acúmulos de $\mathrm{K}$ e $\mathrm{Na}$ na parte aérea e nas raízes de E. contortisiliquum e S. virgata em substituição crescente de K por $\mathrm{Na}$ em solução nutritiva de Hoagland e Arnon.

\section{MATERIAL E MÉTODOS}

O ensaio foi realizado em casa de vegetação, no Departamento de Ciência do Solo da Universidade Federal de Lavras (UFLA), em Lavras, MG, utilizando duas espécies florestais, durante o período de outubro a novembro de 2009. O esquema fatorial foi $2 \times 5$, sendo duas espécies florestais (E. contortisiliquum e $S$. virgata) e cinco níveis de substituição de K por $\mathrm{Na}(0 ; 33,3 ; 50 ; 66,6$; e 100\%) na solução nutritiva de Hoagland e Arnon (1950). Cada tratamento foi composto por quatro repetições, sendo cultivada uma planta por parcela, totalizando 40 unidades experimentais.

As sementes de S. virgata foram adquiridas foram adquiridas no Laboratório de Microbiologia e Bioquímica do Solo, no Departamento de Ciência do Solo (DCS/ UFLA), enquanto as sementes de E. contortisiliquum foram adquiridas no Departamento de Ciências Florestais 
(DCF/UFLA). Inicialmente, as sementes das duas espécies foram submetidas a um processo de escarificação para quebra da dormência. As sementes de E. contortisiliquum e $S$. virgata foram submetidas ao tratamento com ácido sulfúrico $\left(\mathrm{H}_{2} \mathrm{SO}_{4}\right.$ puro para análise $)$ por 45 e $50 \mathrm{~min}$, respectivamente, e depois lavadas com água destilada e deixadas em repouso por $1 \mathrm{~h}$. As sementes de cada espécie foram dispostas separadamente em placas estéreis sobre uma camada dupla de papel-filtro previamente umedecida com água destilada (VIEIRA; BARROS, 2008). As plântulas recém-emergidas foram colocadas em vasos Leonard com capacidade para $1 \mathrm{~L}$, com força iônica de $40 \%$ da solução nutritiva (HOAGLAND; ARNON, 1950). A realização da troca da solução foi realizada a cada sete dias, e a partir da terceira troca a força ionnica passou para $100 \%$. A reposição da água perdida pela evapotranspiração foi realizada diariamente.

Aos 50 dias após a germinação, procedeu-se à colheita das mudas, sendo avaliados a altura de plantas (AP), o número de folhas (NF), o diâmetro do caule (DC), o volume (VR) e o comprimento das raízes (CR). $\mathrm{O}$ material vegetal foi individualmente submetido à lavagem em água corrente e destilada, sendo colocados em sacos de papel e secos em estufa $\left(65-70^{\circ} \mathrm{C}\right)$ até atingir a massa constante. Após a secagem, o material foi mensurado em balança analítica, obtendo-se a matéria seca das folhas (MSF), do caule (MSC) e das raízes (MSR). As folhas e o caule foram unidos, formando a matéria seca da parte aérea (MSPA). A MSPA e a MSR foram trituradas em moinho tipo Willey e submetidas às análises de $\mathrm{K}$ e Na, segundo a metodologia descrita por Malavolta et al. (1997). Por cálculos, foram obtidos a relação raízes/parte aérea (RRPA) e os acúmulos de $\mathrm{K}$ e $\mathrm{Na}$ na parte aérea e nas raízes.

Os resultados foram submetidos à análise de variância e, quando significativos, foram geradas as equações de regressão utilizando o programa estatístico SigmaPlot 11.0 e o teste de médias entre as espécies pelo SISVAR (FERREIRA, 2000).

\section{RESULTADOS}

A AP (Figura 1A) diferiu com a substituição de K por Na na solução nutritiva nas duas espécies, enquanto o NF (Figura 1B) foi uma característica que não sofreu influência. Similarmente a AP, o DC também apresentou diferença em relação aos tratamentos (Figura 1C). O
VR (Figura 1D) obteve incremento significativo entre as substituição de $\mathrm{K}$ por $\mathrm{Na}$ de 33,3 a $66,6 \%$. O CR foi pouco influenciado, com respostas similares entre as duas espécies avaliadas (Figura 1E). Quanto à relação RRPA, a S. virgata e o E. contortisiliquum apresentaram resultados distintos (Figura $1 \mathrm{~F}$ ).

A MSF (Figura 2A), a MSC (Figura 2B), a MSPA (Figura 2C) e a MSR (Figura 2D) de mudas de $E$. contortisiliquum e $S$. virgata foram influenciadas pela substituição de $\mathrm{K}$ por $\mathrm{Na}$, com ganhos maiores para a segunda espécie, no entanto com redução acentuada quando a substituição de K por $\mathrm{Na}$ foi total. Na Tabela 1 são apresentados os resultados médios das características agronômicas avaliadas no estudo e mostrado que a $S$. virgata apresenta maior desenvolvimento inicial do que em relação ao E. contortisiliquum.

Os teores e acúmulos de K na parte aérea (Figura $3 \mathrm{AB}$, respectivamente) e nas raízes (Figura 3CD, respectivamente) apresentaram diferença significativa entre os tratamentos. Nos teores de K, houve redução dos teores da parte aérea nas duas espécies e ligeiro aumento nas raízes até a substituição de $50 \%$ em E. contortisiliquum e redução acentuada em $S$. virgata. O acúmulo de K refletiu a MSPA (Figura 2C) e MSR (Figura 2D), com maiores incrementos entre a substituição de 50 e 66,6\% do K pelo $\mathrm{Na}$ em $S$. virgata, sendo em E. contortisiliquum esse aumento pouco pronunciado.

Os teores de $\mathrm{Na}$ na parte aérea (Figura 3E) aumentaram com o incremento da concentração do elemento na solução nutritiva, independentemente da espécie e do compartimento da planta. A curva de acúmulo de Na na $S$. virgata foi semelhante a MSPA, enquanto em E. contortisiliquum foi linear (Figura 3F). Ao contrário do observado para o $\mathrm{K}$, os teores de $\mathrm{Na}$ nas raízes (Figura $3 \mathrm{G}$ ) aumentaram com o incremento de $\mathrm{Na}$ na solução nutritiva. Assim, o acúmulo de $\mathrm{Na}$ nas raízes (Figura $3 \mathrm{H}$ ) foi maior em $S$. virgata devido à maior MSPA (Figura 2C) e MSR (Figura 2D), além do fato de os maiores teores de Na nas raízes (Figura 1G) serem maiores que em E. contortisiliquum.

$\mathrm{Na}$ avaliação dos teores e acúmulos de $\mathrm{K}$ e $\mathrm{Na}$ nas duas espécies (Tabela 2), observou-se que S. virgata possui maior capacidade de acúmulo de K e Na na MSPA, enquanto $E$. contortisiliquum concentrou mais o $\mathrm{K}$ na MSR, não diferindo para o Na entre as espécies. As mudas de $S$. virgata apresentaram melhor 

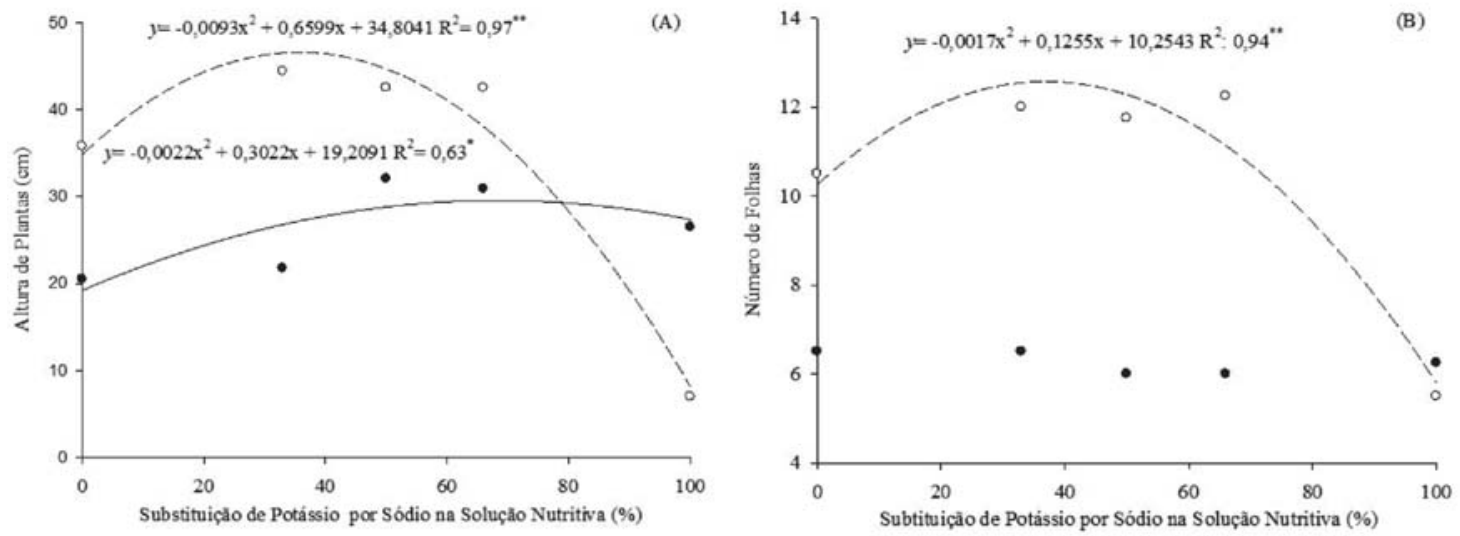

- Enterolobium contortisiliquen

Sesbania virgata

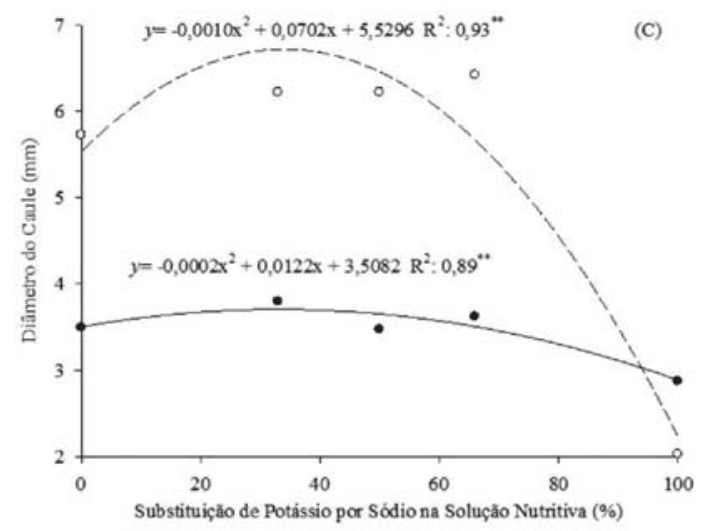

- Enterolobitun contortisiliquion

- Sesbania virgata

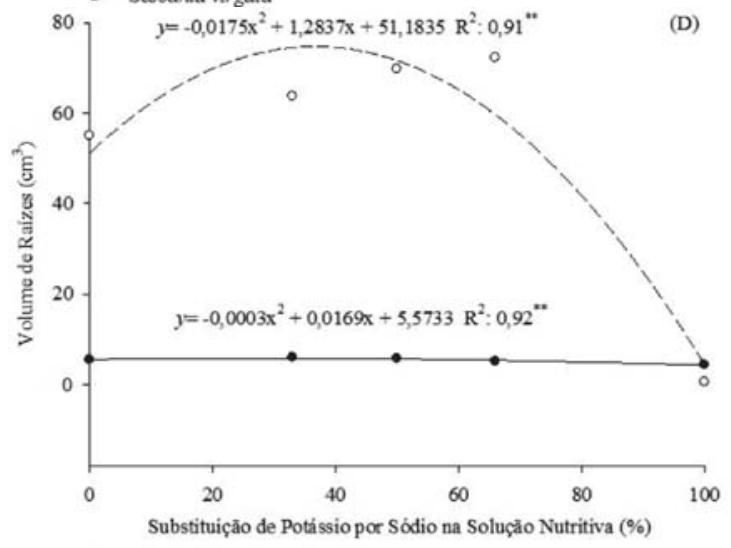

Enterolobium contortisiliquzen

Sesbaria vingata

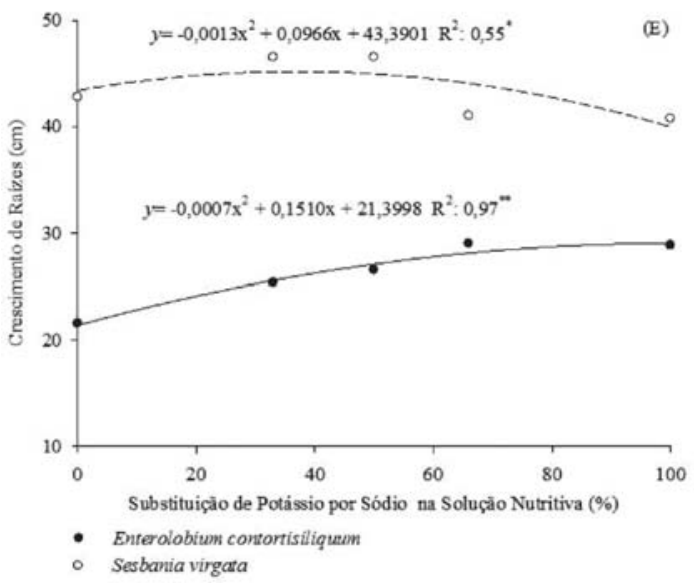

- Enterolobiton contortisiliquam

- Sesbania virgata

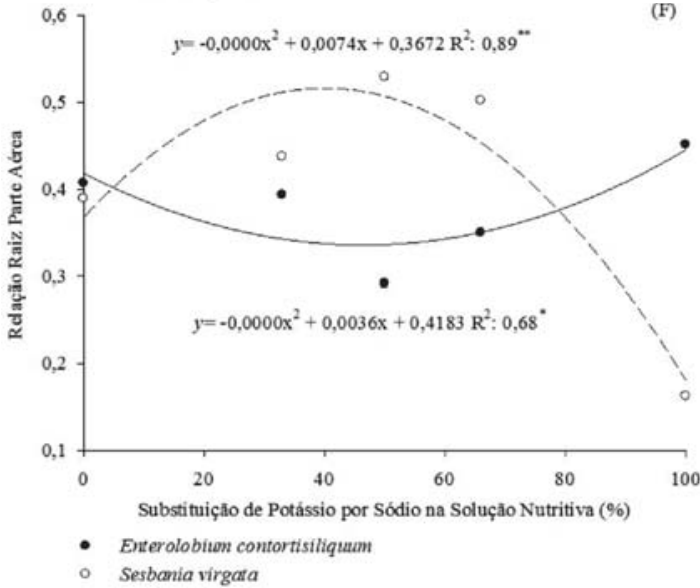

Figura 1 - Altura de plantas (A), número de folhas (B), diâmetro do caule (C), volume de raízes (D), crescimento de raízes (E) e relação raiz/parte aérea (F) de Enterolobium contortisiliquum e Sesbania virgata em substituição de potássio por sódio na solução nutritiva de Hoagland e Arnon.

Figure 1 - Plant height (A), leaf number (B), stem diameter (C), root volume (D), root growthand (E) and root / shoot cuttings $(F)$ of Enterolobium contortisiliquum and Sesbania virgata cultivated under replacement of potassium by sodium in the Hoagland e Arnon nutrient solution.

Revista Árvore, Viçosa-MG, v.38, n.1, p.113-123, 2014 
desenvolvimento em todas as características avaliadas em relação a E. contortisiliquum e, com isso, resulta no maior acúmulo de $\mathrm{K}$ e $\mathrm{Na}$ na MSPA.

\section{DISCUSSÃO}

\subsection{Características morfométricas}

Com o incremento da substituição de $\mathrm{K}$ por $\mathrm{Na}$ até $50 \%$, as duas espécies apresentaram aumento na AP (Figura 1A), onde provavelmente ocorreu

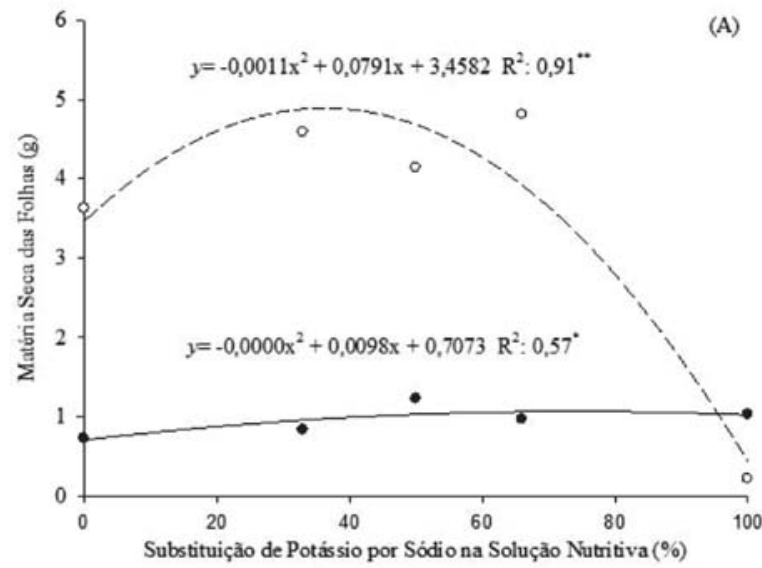

Enterolobium contortisiliquum

- Sesbaria virgata

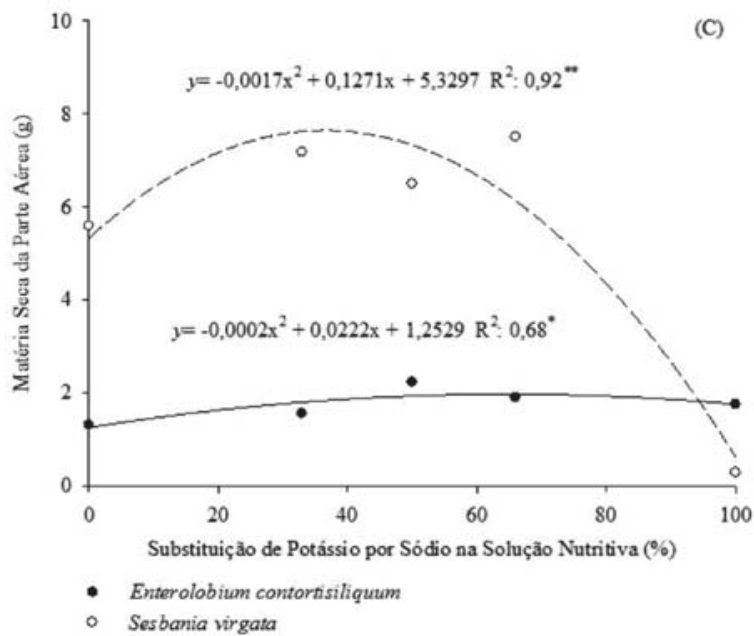

aumento da permeabilidade da membrana citoplasmática, desencadeando na maior absorção de nutrientes (FAQUIN, 2005). No caso da substituição completa do K, algumas enzimas ativadas exclusivamente pelo $\mathrm{K}$ podem ter deixado de realizar suas funções vitais, especialmente no crescimento de S. virgata. Além do aumento da absorção de nutrientes e ativação enzimática, o Na pode ter atuado na osmorregulação, na síntese de carboidratos e no transporte de $\mathrm{CO}_{2}$ (KORNDORFER, 2007). Além da
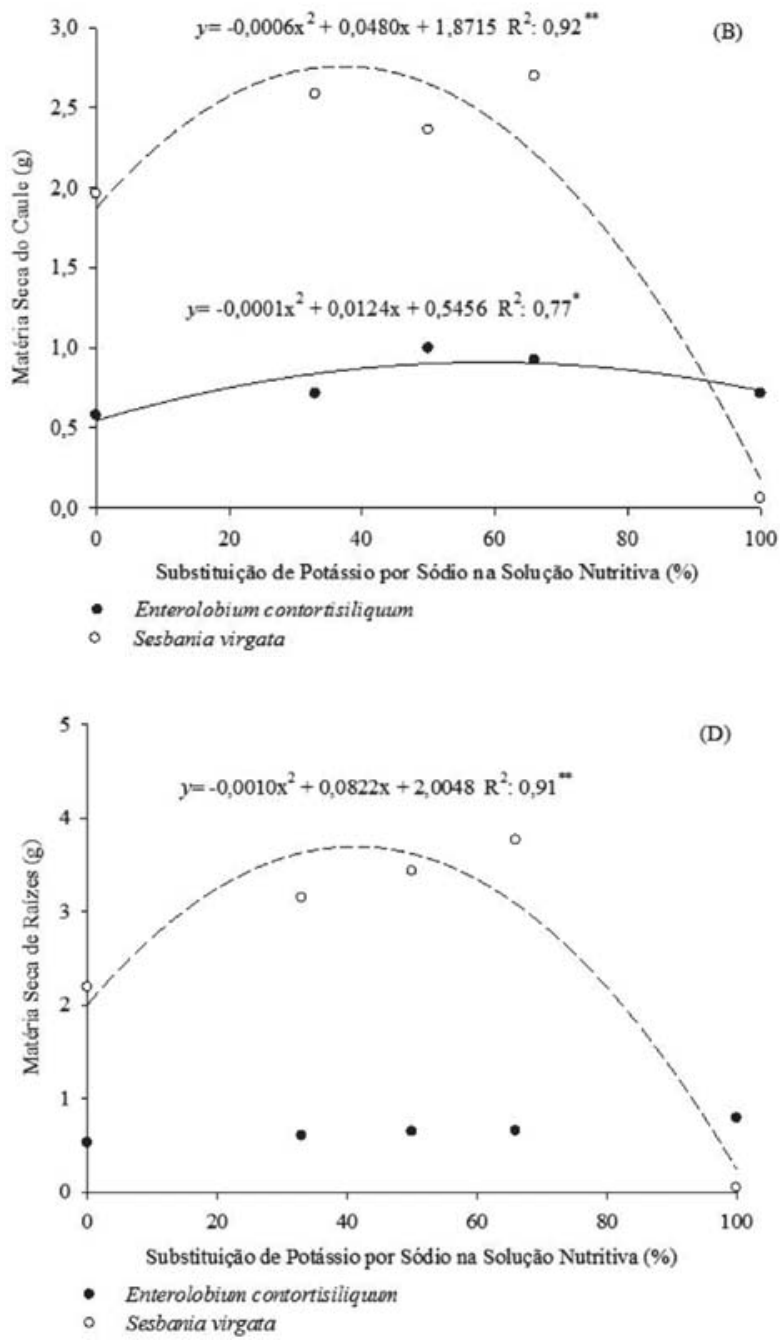

Figura 2 - Produtividade de matéria seca de folhas (A), caule (B), parte aérea (folhas + caule) (C) e raízes (D) de mudas de Enterolobium contortisiliquum e Sesbania virgata em substituição de potássio por sódio na solução nutritiva de Hoagland e Arnon.

Figure 2 - Dry matter productiviry on leaves (A), stem (B), shoot (leaves + stem)(C) and roots (D) of Enterolobium contortisiliquum and Sesbania virgata cultivated under replacement of potassium by sodium in the Hoagland and Arnon nutrient solution. 

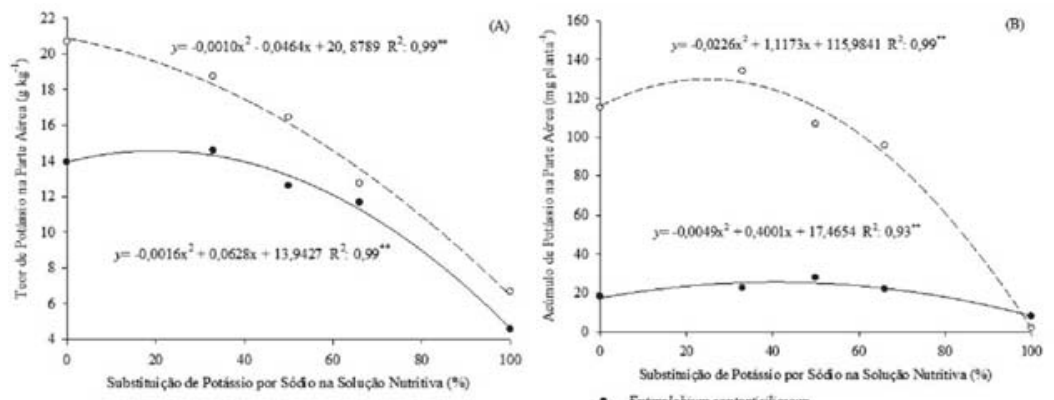

- Enterolabivin contoristipum
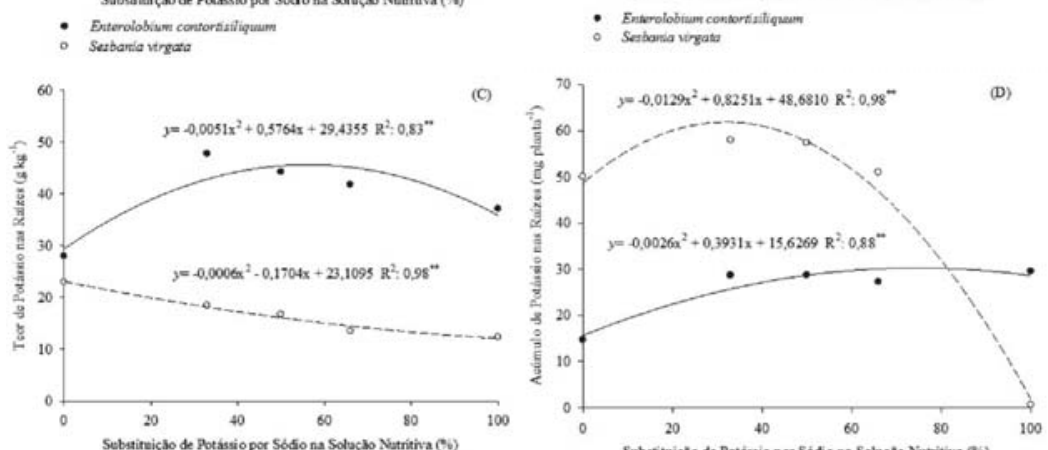

- Encerobitim contoratiliquen

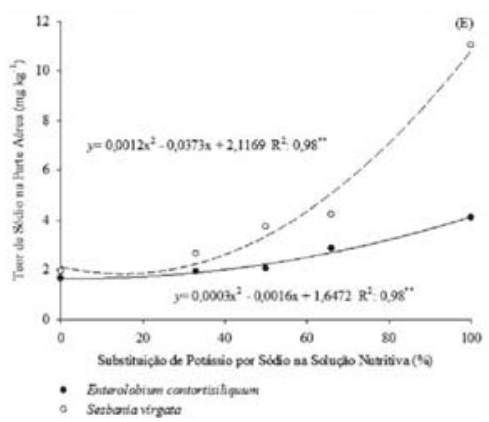

- Enterolobisun cantortintiquer

Enterolobinum cant
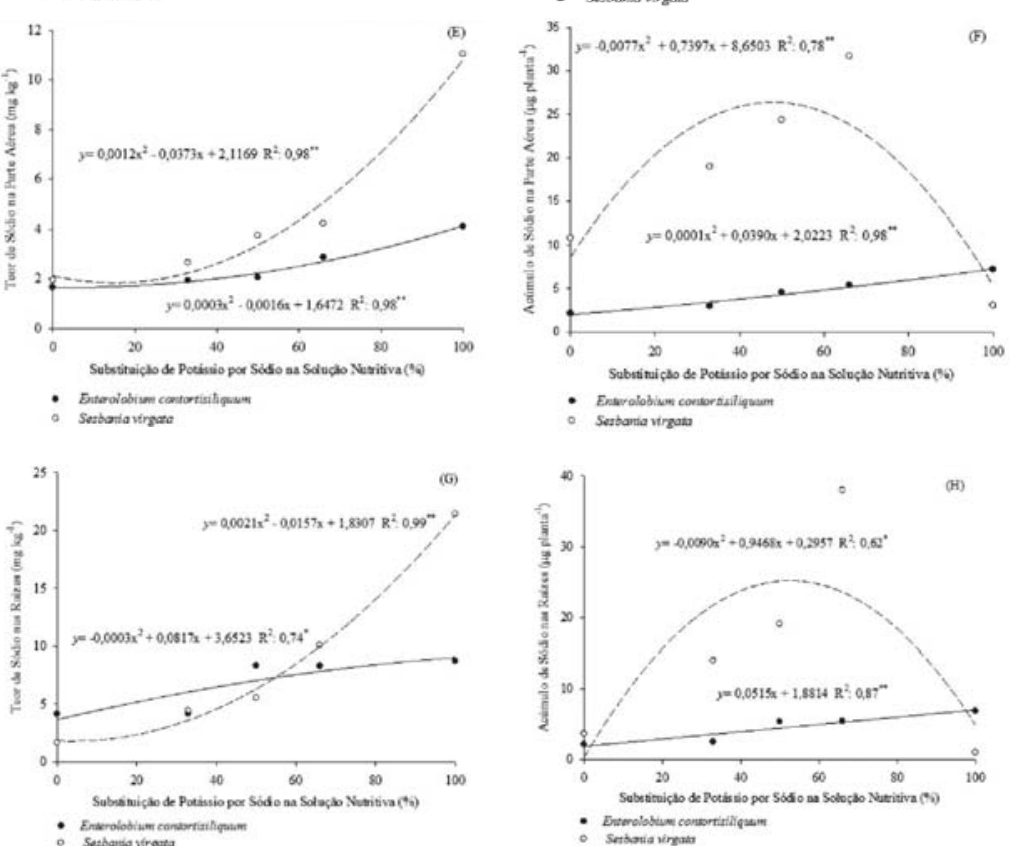

Figura 3 - Teores de potássio na matéria seca da parte aérea (A) e raízes (B) e acúmulo da matéria seca da parte aérea (C) e raízes (D), teores de sódio na matéria seca da parte aérea (E) e raízes (F) e acúmulo da matéria seca da parte aérea $(\mathrm{G})$ das raízes $(\mathrm{H})$ em Enterolobium contortisiliquum e Sesbania virgata em substituição de potássio por sódio na solução nutritiva de Hoagland e Arnon.

Figure 3 - Potassium content in dry matter of shoot (A) and roots (B) and accumulation of dry matter on shoots (C) and roots (D). sodium content in the dry matter of shoots ( $E)$ and roots $(F)$, and dry matter accumulation on shoots $(G)$ and roots $(H)$ of Enterolobium contortisiliquum and Sesbania virgata, under replacement of potassium by sodium in the Hoagland and Arnon nutrient solution.

Revista Árvore, Viçosa-MG, v.38, n.1, p.113-123, 2014 
redução do crescimento das plantas no tratamento com ausência de K, as folhas de S. virgata apresentaram amarelecimento e necrose nos bordos das folhas (FAQUIN, 2005; MEURER, 2006). AAP de S. virgata até os 30 dias após a germinação foi pouco acentuada e, a partir desse período, o crescimento foi acelerado e, no final do ensaio, maior que a AP de $E$. contortisiliquum, que praticamente anulou o crescimento nos últimos 20 dias, especialmente nos tratamentos com substituição acima de 33,3\%. Esses resultados são semelhantes aos encontrados por Silva et al. (2008), estudando o crescimento de mamoneira (Ricinus communis L.) sob estresse salino, e aos de Soares et al. (2007). Esse fato pode ser devido à maior reserva de nutrientes da segunda espécie, em que a massa de 100 sementes é de $83,85 \mathrm{~g}$, mais de 10 vezes superior à de $S$. virgata, que é de 7,37 .
O NF (Figura 2B) de S. virgata seguiu a AP, o que pode estar associado ao desenvolvimento normal da planta, sem o processo de elongação ou encurtamento dos internódios (TAIZ; ZEIGER, 2004). Korndorfer (2007) afirmou que $25 \%$ de $\mathrm{Na}$ no total dos cátions básicos acarreta problemas severos de fitotoxicidade, como ocorreu no tratamento com substituição de $100 \%$ de K por Na de S. virgata, em que, possivelmente, não houve a ativação de enzimas que tem o K como o seu grupo prostético (FAQUIN, 2005). Em níveis elevados de $\mathrm{Na}$, o controle osmótico é prejudicado devido à absorção excessiva de $\mathrm{Na}$ em detrimento do $\mathrm{Ca}$, que é responsável pela manutenção da permeabilidade seletiva das membranas, por ser constituinte da lamela média na forma de pectatos de cálcio (HANSEN; MUNNS, 1988). Assim, o Na em altas concentrações pode interferir na absorção de $\mathrm{Ca}$ e $\mathrm{Mg}$, pela competição dos mesmos

Tabela 1 - Avaliação das características morfométricas de mudas de Enterolobium contortisiliquum e Sesbania virgata, cultivadas sob a substituição de potássio por sódio.

Table 1 - Assessment of morphometric characteristics of Enterolobium contortisiliquum and Sesbania virgata seedlings cultivated under replacement of potassium by sodium.

\begin{tabular}{|c|c|c|c|c|c|}
\hline Espécie & $\mathrm{AP}(\mathrm{cm})$ & $\mathrm{NF}\left(\mathrm{n}^{\mathrm{o}}\right)$ & $\mathrm{DC}(\mathrm{mm})$ & $\operatorname{VR}\left(\mathrm{cm}^{3}\right)$ & $\mathrm{CR}(\mathrm{cm})$ \\
\hline Enterolobium & $26,33 \mathrm{~b}$ & $6,25 \mathrm{~b}$ & $3,46 \mathrm{~b}$ & $5,35 \mathrm{~b}$ & $26,25 \mathrm{~b}$ \\
\hline \multirow[t]{2}{*}{ Sesbania } & 34,43 a & $10,40 \mathrm{a}$ & 5,33 a & 52,27 a & $43,50 \mathrm{a}$ \\
\hline & $\operatorname{MSF}(\mathrm{g})$ & $\operatorname{MSC}(\mathrm{g})$ & MSPA (g) & $\operatorname{MSR}(\mathrm{g})$ & RRPA \\
\hline Enterolobium & $0,96 \mathrm{~b}$ & $0,79 \mathrm{~b}$ & $1,74 \mathrm{~b}$ & $0,64 \mathrm{~b}$ & $0,38 \mathrm{a}$ \\
\hline Sesbania & $3,74 \mathrm{a}$ & 1,93 a & 5,41 a & $2,52 \mathrm{a}$ & $0,40 \mathrm{a}$ \\
\hline
\end{tabular}

AP: altura de plantas; NF: número de folhas; DC: diâmetro do caule; VR: volume de raízes; CR: comprimento de raiz; MSF: matéria seca das folhas; MSC: matéria seca do caule; MSPA: matéria seca da parte aérea; MSR: matéria seca das raízes; e RRPA: relação raiz/ parte aérea. Médias seguidas pela mesma letra na coluna na mesma espécie não diferem estatisticamente entre si, pelo teste de Tukey a $5 \%$ de probabilidade.

Tabela 2 - Avaliação dos teores de potássio e sódio na matéria seca da parte aérea e nas raízes de mudas de Enterolobium contortisiliquum e Sesbania virgata, cultivadas sob a substituição de potássio por sódio.

Table 2-Evaluation of the levels of potassium and sodium in the dry matter of shoots and roots of Enterolobium contortisiliquum and Sesbania virgata, cultivated under replacement of potassium by sodium.

\begin{tabular}{|c|c|c|c|c|}
\hline \multirow[b]{2}{*}{ Espécie } & \multicolumn{2}{|c|}{ Potássio } & \multicolumn{2}{|c|}{ Sódio } \\
\hline & $\begin{array}{c}\text { Teor } \\
\left(\mathrm{g} \mathrm{kg}^{-1}\right)\end{array}$ & $\begin{array}{c}\text { Acúmulo } \\
\left(\mathrm{mg} \mathrm{planta}^{-1}\right)\end{array}$ & $\begin{array}{c}\text { Teor } \\
\left(\mathrm{mg} \mathrm{kg}^{-1}\right)\end{array}$ & $\begin{array}{c}\text { Acúmulo } \\
\left(\mu \mathrm{g} \mathrm{planta}^{-1}\right)\end{array}$ \\
\hline & \multicolumn{4}{|c|}{ Matéria seca da parte aérea } \\
\hline Enterolobium contortisiliquum & $11,47 \mathrm{bB}$ & $19,70 \mathrm{bB}$ & $2,52 \mathrm{bB}$ & $4,45 \mathrm{bA}$ \\
\hline \multirow[t]{2}{*}{ Sesbania virgata } & 15,05 aA & 90,65 aA & $4,72 \mathrm{aB}$ & 17,76 aA \\
\hline & \multicolumn{4}{|c|}{ Matéria seca de raízes } \\
\hline Enterolobium contortisiliquum & 39,76 aA & $25,75 \mathrm{bA}$ & 6,71 aA & $4,56 \mathrm{bA}$ \\
\hline Sesbania virgata & $16,79 \mathrm{bA}$ & 43,36 aB & 8,62 aA & 15,11 aA \\
\hline
\end{tabular}

Médias seguidas pela mesma letra minúscula na coluna apenas entre cada característica avaliada e letra maiúscula na coluna na mesma espécie não diferem estatisticamente entre si, pelo teste de Tukey a $5 \%$ de probabilidade. 
sítios de absorção das raízes, porém em concentrações baixas pode estimular a absorção desses nutrientes (MARSCHNER, 1995).

Nos tratamentos, o DC (Figura 1C) das espécies avaliadas refletiu a influência dos tratamentos, pois grande parte do Ca está presente na parede celular em tecidos mais lignificados, através de pectatos de cálcio (FAQUIN, 2005). O VR (Figura 1D) apresentou incremento significativo com a substituição de até 66,6 de K por Na, especialmente na S. virgata. Esses ganhos significativos podem estar relacionados ao efeito benéfico do $\mathrm{Na}$ em algumas plantas (KORNDORFER, 2007), assim como apresentado nas outras características avaliadas, enquanto no CR (Figura 1E) foi observada pequena redução no crescimento de raízes de $S$. virgata e aumento em E. contortisiliquum. Assim, para o CR, a $S$. virgata apresentou maior sensibilidade à falta de K no tratamento de $100 \%$ de $\mathrm{Na}$ em todas as características avaliadas (MEURER, 2006) em relação a E. contortisiliquum. Como o tempo do experimento foi de 50 dias, a resposta do E. contortisiliquum foi pouco acentuada, mas, caso a duração do ensaio fosse maior, o efeito do $\mathrm{K}$ acúmulo nas sementes se esgotaria e os sintomas de deficiência de K poderiam se tornar mais evidentes (SOARES et al., 2007).

Para a RRPA (Figura 1F), as duas espécies apresentaram respostas opostas, sendo na literatura essa relação maior nas condições de deficiência, em que os fotoassimilados são direcionados ao sistema radicular em detrimento da parte aérea e, assim, as raízes exploram maior volume de solo, absorvendo água e nutrientes (FURTINI NETO et al., 2000; FERNANDES et al., 2007). Já para Carneiro et al. (2002) houve aumento linear na relação RRPA pela elevação da salinidade da água de irrigação em cajueiro-anão (Anacardium occidentale L.).

S. virgata teve seu crescimento radicular dependente do desenvolvimento da MSF (Figura 2A) e MSC (Figura 2B), com incrementos a partir da elevação dos teores de Na na solução nutritiva. Enquanto em E. contortisiliquum os incrementos foram menos acentuados, em outros estudos a presença de $\mathrm{Na}$, além do nível considerado adequado, promoveu a redução da MSPA (BLANCO et al., 2002). A perda de água pelas raízes e a competição do Ca pelo $\mathrm{Na}$ (quando em excesso) provoca a perda da permeabilidade, acarretando a entrada excessiva de Na (HANSEN; MUNNS, 1988; MARSCHNER, 1995). O desenvolvimento das plantas depende diretamente da demanda por água em todo o seu ciclo. Nesse sentido, em condições de estresse hídrico a osmorregulação é característica importante para o balanço hídrico da planta (KRIEG, 1993) e o K é o nutriente responsável por esse processo, embora o Na possa assumir essa função (FAQUIN, 2005).

Sem a substituição de $\mathrm{K}$ por $\mathrm{Na}$, as mudas apresentavam pleno fornecimento dos nutrientes, porém $\mathrm{o}$ incremento de $\mathrm{Na}$ na solução em detrimento de $\mathrm{K}$ gerou um balanço positivo, pois favoreceu a absorção de nutrientes (dados não apresentados), em que a taxa de crescimento da parte aérea (Figura 2C) foi superior ao do sistema radicular (Figura 2D). Apenas para substituição completa do K houve semelhança com Carneiro et al. (2002), pois a parte aérea foi mais prejudicada do que as raízes. A redução da parte aérea foi maior, visto que a planta como estratégia de sobrevivência provavelmente direcionou os fotoassimilados para o CR (Figura 1E), mas na ausência de K na solução nutritiva o desenvolvimento foi pouco pronunciado (FURTINI NETO et al., 2000; FERNANDES et al., 2007).

A partir das informações obtidas neste estudo e pela classificação citada por Faquin (2005) e Korndorfer (2007), a S. virgata e o E. contortisiliquum podem ser classificadas como plantas dos grupos I e II, respectivamente. As plantas do grupo I correspondem àquelas que possuem incremento na produtividade pela substituição do K pelo $\mathrm{Na}$, o que não seria alcançado com o aumento das doses de K, e as do grupo II, ao aumento na produtividade, porém inferior às do grupo I. Essas plantas apresentam melhor metabolismo quando o Na está presente na solução. Marschner (1995) afirmou que essa resposta do $\mathrm{Na}$ só acontece desde que se tenham um mínimo necessário de $\mathrm{K}$, pois algumas reações enzimáticas só acontecem na presença desse nutriente. Essas duas leguminosas possuem resistência à elevada concentração de Na no solo em razão, provavelmente, de algumas alterações anatômicas, fisiológicas ou metabólicas (TAIZ;ZEIGER, 2004). Algumas características podem ser mencionadas, como o ajuste osmótico, o aumento do teor de água nos tecidos (efeito diluição), a formação de grânulos de sal e a compartimentação iônica (LARCHER, 2000).

Para avaliar os resultados das diferentes características agronômicas das duas espécies florestais, foi realizado um teste de média, com o qual se obteve diferença para todas as características avaliadas, exceto o RRPA (Tabela 1). As plantas de S. virgata apresentaram 
maiores valores em todas as características avaliadas em relação ao E. contortisiliquum, o que resultou em maior acúmulo de $\mathrm{K}$ e Na na biomassa das plantas.

\subsection{Teor e acúmulo de K e Na na biomassa}

Com a substituição do K por Na na solução nutritiva houve menores teores (Figura 3A) e acúmulo (Figura 3B) de K na MSPA (MEURER, 2006), nas duas espécies estudadas. Porém, na MSR, apenas S. virgata teve redução linear do teor de K, enquanto em E. contortisiliquum houve resposta quadrática e teores mais elevados do que a outra espécie (Figura 3C). Apesar do menor teor de K no sistema radicular, S. virgata apresentou maior acúmulo (Figura 3D), devido à maior MSR (Figura 2D), que é uma característica importante, principalmente em solos pobres. Isso porque houve aumento no volume de solo explorado e pode haver a recuperação do K e de outros nutrientes, que foram perdidos por lixiviação, realizando, dessa forma, uma biociclagem (FURTINI NETO et al., 2007).

Os resultados deste estudo para os teores de K diferem dos de Meurer (2006), em que S. virgata não apresentou diferença entre os teores de K na MSPA (Figura 3A) e nas MSR (Figura 3C), enquanto em E. contortisiliquum foi maior na MSR. Esse autor relatou que os teores de $\mathrm{K}$ tendem a ser maiores na MSPA em relação à MSR, devido à alta mobilidade do nutriente. $S$. virgata requer maior quantidade de K para o seu desenvolvimento em relação ao E. contortisiliquum, pois sua taxa de crescimento é maior (ARAÚJO et al., 2004). O desenvolvimento da planta é ligado à síntese proteica, sendo nas etapas para sua formação necessário o K como ativador de algumas enzimas (MARSCHNER, 1995; MEURER, 2006). Os maiores teores de K nas raízes em relação à parte aérea podem ser estratégia de defesa contra o excesso de $\mathrm{Na}$ na solução.

No caso de K, S. virgata apresentou maiores teores na MSPA(Figura 3E). Mesmo com isso, o seu crescimento foi rápido, com alto acúmulo de Na na MSR (Figura 1F), sem apresentar sintomas de toxidez na parte aérea, exceto no tratamento com substituição total do K pelo Na. À semelhança do K, os teores de $\mathrm{Na}$ foram maiores na MSR(Figura 1G), aproximadamente de duas vezes e também no acúmulo de Na nesse compartimento (Figura $1 \mathrm{H}$ ) em razão, principalmente, da MSR (Figura 2D). Dessa forma, as duas espécies demonstraram uma estratégia contra o excesso de $\mathrm{Na}$, acumulando nas raízes (FERNANDES et al., 2007). Dessa forma, o Na nas raízes atuaria no aumento da absorção de nutrientes catiônicos, como Ca e $\mathrm{Mg}$, uma vez que o $\mathrm{K}$ possui interação competitiva com esses cátions (MEURER, 2006). Mas nem sempre o acúmulo de algum nutriente nas raízes é uma estratégia contra a toxidez. Ramos et al. (2009) observaram que, em condições de menor disponibilidade hídrica, o boro teve maior acúmulo no sistema radicular em relação a bons níveis de água no solo, por causa de que esse nutriente tem sua mobilidade influenciada pelo fluxo de massa. Porém, em plantas que possuem baixa tolerância ao $\mathrm{Na}$, é alta a translocação para a parte aérea e, com isso, interfere no metabolismo primário da planta (KORNDORFER, 2006). Dessa forma, o Na tem como função melhorar a absorção de nutrientes e, de forma secundária, a substituição parcial do K em algumas atividades metabólicas e fisiológicas das plantas (LARCHER, 2000).

Na Tabela 2, S. virgata apresenta maior translocação do $\mathrm{K}$ das raízes para a parte aérea do que E. contortisiliquum. No entanto, elevados teores de nutrientes nos tecido das plantas não indicam aumento de produtividade (RAMOS et al., 2009), sendo essas diferenças relacionadas ao próprio genótipo (TAIZ; ZEIGER, 2004). Lacerda et al. (2004), em avaliação de genótipos de sorgo (Sorghum bicolor) em condições de estresse salino e doses de $\mathrm{Ca}$, concluíram que sob altas doses de Ca há redução no efeito maléfico do excesso de $\mathrm{Na}$, auxiliando, assim, a absorção dos outros nutrientes. Além da diminuição no crescimento da planta de sorgo, houve maior absorção de $\mathrm{Na}$ e $\mathrm{Cl}$ e redução na absorção de $\mathrm{K}$ e Ca.

A procura por genótipos mais tolerantes e resistentes para a utilização em programas de reflorestamento ou de recuperação de áreas degradadas é uma das estratégias mais promissoras, visto que são solos de baixa fertilidade natural ou que sofreram processo erosivo intenso. Resende et al. (1999), avaliando o crescimento inicial de genótipos de essências florestais de três grupos sucessionais em resposta à adubação fosfatada, observaram a importância da obtenção de mudas com rápido crescimento inicial para o restabelecimento do ecossistema a ser recuperado. O efeito benéfico de $S$. virgata na recuperação da fertilidade do solo promove o estabelecimento de plantas da sequência sucessional (GRIFFITH et al., 2000). Com os resultados, pode-se considerar S. virgata uma espécie potencial para a revegetação de áreas com teores elevados de sais naturalmente (MEGNELLO; MARTEI, 2004; SOARES 
et al., 2007; MELO et al., 2008), como os encontrados na Região Nordeste (GHEYI; FAGERIA, 1997) ou em áreas onde foram submetidos a um manejo inadequado com o uso de água de irrigação rica em sais (BLANCO et al., 2002). Contudo, são necessários estudos com solo que apresente altos teores de $\mathrm{Na}$, a fim de verificar seu comportamento nessa situação, uma vez que a planta apresentou resposta significativa com a substituição de $\mathrm{K}$ por $\mathrm{Na}$ de $50 \%$, em média, para todas as características avaliadas.

\section{CONCLUSÃO}

A substituição de $\mathrm{K}$ por $\mathrm{Na}$ promoveu aumento significativo em todas as características agronômicas para S. virgata e E. contortisiliquum, exceto o NF para a última espécie, em relação à testemunha, com maiores incrementos para S. virgata.

Os teores de $\mathrm{K}$ e $\mathrm{Na}$ na parte aérea foram maiores em S. virgata e de K nas raízes de E. contortisiliquum, não diferindo os teores de Na nas raízes das duas espécies.

S. virgata mostrou-se uma espécie mais eficiente no uso de $\mathrm{K}$ e tolerante ao $\mathrm{Na}$ na solução nutritiva.

$\mathrm{O}$ aumento de $\mathrm{Na}$ na solução nutritiva resultou em aumento na absorção de $\mathrm{Na}$ e redução de K pelas mudas.

\section{REFERÊNCIAS}

ARAÚJO, E. C. et al. Caracterização morfológica de frutos, sementes e plântulas de Sesbania virgata (CAV.) Pers. Revista Brasileira de Sementes, v.26, n.1, p.105-110, 2004.

BLANCO, F. F. et al. Fertirrigação com água salina e seus efeitos na produção do pepino enxertado cultivado em ambiente protegido. Horticultura Brasileira, v.20, n.3, p.442-446, 2002.

CARNEIRO, P. T. et al. Germinação e crescimento inicial de genótipos de cajueiro anão-precoce em condições de salinidade. Revista Brasileira de Engenharia Agrícola e Ambiental, v.6, n.2, p.199-206, 2002.

CHAVES, L. L. B. et al. Efeitos da inoculação nitrogenada na produção de mudas de sesbânia em substrato constituído de resíduos agroindustriais. Revista Árvore, v.27, n.4, p.443-449, 2003.

Revista Árvore, Viçosa-MG, v.38, n.1, p.113-123, 2014
FAQUIN, V. Nutrição mineral de plantas. Lavras: UFLA/FAEPE, 2005. 183p.

FERNANDES, A. R. et al. Crescimento e absorção de nutrientes por mudas de freijó (Cordia goeldiana Huber) em função de doses de fósforo e de zinco. Revista Árvore, v.31, n.4, p.599608, 2007.

FERREIRA, D. F. SISVAR: Sistema de Análise de Variância. Lavras: Universidade Federal de Lavras, 2000.

FURTINI NETO, A. E. et al. Resposta de cultivares de feijoeiro ao enxofre. Pesquisa Agropecuária Brasileira, v.35, n.3, p.567$573,2000$.

GHEYI, H.; FAGERIA, N. K. Efeito dos sais sobre as plantas. In: GHEYI, H. R.; QUEIROZ, J. E.; MEDEIROS, J. M. (Ed.). Manejo e controle da salinidade na agricultura irrigada. Campina Grande: Universidade Federal da Paraíba, 1997. p.125-131.

GRIFFITH, J. J.; DIAS, L. D.; MARCO JÚNIOR, P. A. A recuperação ambiental. Ação Ambiental, v.3, n.10, p.8-10, 2000 .

HANSEN, E. H.; MUNNS, D. N. Effect of $\mathrm{CaSO}_{4}$ and $\mathrm{NaCl}$ on mineral content of Leucaena leucocephala. Plant Soil, v.107, p.101-105, 1988.

HOAGLAND, D. R.; ARNON, D. L. The water culture methods for growing plants without soil. Berkeley: California Agriculture Experiment Station, 1950. 32p. (Bulletin, 347).

KORNDORFER, G. H. Elementos benéficos. In: FERNANDES, M. S. (Ed.) Nutrição mineral de plantas. Viçosa, MG: Sociedade Brasileira de Ciência do Solo, 2006. p.355-374.

KRIEG, D. R. Stress tolerance mechanisms in above ground organs. In: WORKSHOP ON ADAPTATION OF PLANTS TO SOIL STRESS, 1993. Proceedings... Nebraska: INTSORMIL, 1993. p.65-79.

LACERDA, C. F. et al. Influência do cálcio sobre o crescimento e solutos em plântulas de sorgo estressadas com cloreto de sódio. Revista Brasileira de Ciência do Solo, v.28, n.2, p.289-295, 2004. 
LARCHER, W. Ecofisiologia vegetal. São Carlos: Universidade Federal de São Carlos, 2000. 531p.

LORENZI, H. Árvores brasileiras: manual de identificação e cultivo de plantas arbóreas nativas do Brasil. 2.ed. Nova Odessa: Plantarum, 1998. 352p.

MALAVOLTA, E.; VITTI, G. C.; OLIVEIRA, S. A Avaliação do estado nutricional das plantas: princípios e aplicações. Piracicaba: Potafos, 1997. 319p.

MARSCHNER, H. Mineral nutrition of higher plants. New York: Academic Press, 1995. 889p.

MELO, R. R. et al. Crescimento inicial de mudas de Enterolobium contortisiliquum (Vell.) Morong sob diferentes níveis de luminosidade. Agrária, v.3, n.2, p.138-144, 2008.

MENEGHELLO, G. E.; MATTEI, V. L. Semeadura direta de timbaúva (Enterolobium contortisiliquum), canafístula (Peltophorum dubium) e cedro (Cedrela fissilis) em campos abandonados. Ciência Florestal, v.14, n.2, p.21-27, 2004.

MEURER, E. J. Potássio. In: FERNANDES, M. S. (Ed.) Nutrição mineral de plantas. Viçosa, MG: Sociedade Brasileira de Ciência do Solo, 2006. p.281-298.

RAMOS, S. J. et al. Crescimento e teores de boro em plantas de eucalipto (Eucaliptus citriodora) cultivadas em dois Latossolos sob influência de doses de boro e disponibilidade de água.

Revista Árvore, v.33, n.1, p.57-65, 2009.
RESENDE, A. V. et al. Crescimento inicial de espécies florestais de diferentes grupos sucessionais em resposta a doses de fósforo. Pesquisa Agropecuária Brasileira, v.34, n.11,p.2071-2081, 1999.

SILVA, S. M. S. et al. Desenvolvimento e produção de duas cultivares de mamoneira sob estresse salino. Revista Brasileira de Engenharia Agrícola e Ambiental, v.12, n.4, p.335-342, 2008.

SOARES, D. A.; NORMANDO, L. R. O.; GALLÃO, M. I. Mobilização de reservas de Enterolobium contortisiliquum (Vell.) Morong durante a germinação. In: CONGRESSO DE ECOLOGIA DO BRASIL, 8., 2007, Caxambu. Anais... Caxambu: 2007.

SOUZA, M. R. Comportamento do feijoeiro (Phaseolus vulgaris $\mathrm{L}$. CV Eriparza) submetido a diferentes níveis de salinidade da água de irrigação. 1995. 94p. Dissertação (Mestrado em Engenharia Agrícola) - Universidade Federal de Lavras, Lavras, 1995. 94p.

TAIZ, L.; ZEIGER, E. Fisiologia vegetal. 3.ed. Porto Alegre: Artmed, 2004. 719p.

VIEIRA, E. A.; BARROS, A. L. Superação de dormência e profundidade de semeadura de sementes de Enterolobium contortisiliquum (Vell.) Morang Leguminosae. In: SIMPÓSIO NACIONAL CERRADO, 9.; SIMPÓSIO

INTERNACIONAL SAVANAS TROPICAIS, 2., 2008 , Brasília. Anais... Brasília: 2008. 
